\title{
The Effect of Networking Revolution on Digital Music
}

\author{
Margounakis Dimitrios, Politis Dionysios \\ Computer Science Department, Aristotle University of Thessaloniki \\ Thessaloniki, Greece
}

\begin{abstract}
The way people consume music in our days has totally changed as a result of the current developments in hardware and software, as well as the evolution of the Internet. People do not buy CDs or records anymore. Nowadays, people store music data on their disks and listen to music via portable devices (i-pods, mobile phones etc.). However, the advent of Web 2.0 foretokens colossal changes in the fields of music production, distribution and management. Cloud computing, social networks and web-based operating systems are some of the recent trends that affect these fields and introduce a new era beyond MP3.
\end{abstract}

\section{Introduction}

In the last few years, the Internet users' community has experienced huge changes in the way the web sites function and the services they offer. There is a new logic behind this evolution that goes beyond the data-based web structures of the near past. The new networking trend invites users not as passive receivers of information, but as creators, or at least gatherers and redistributors.

Representative web pages of the modern networking era are: blogs, wikis and social networks. Blogs (or Web logs) are web sites used for the recording and chronological presentation of journaltype recordings. They can combine text, images and hyperlinks, while posting an entry is extremely easy. While blogs facilitate the expression of a single person, wikis, on the other hand, facilitate collaboration and common understanding. Wikis are web applications that allow collaborative content authoring. The most well-known wiki application is the online collaborative encyclopedia Wikipedia. Finally, social networks have become prevalent in the age of the Web. With interfaces that allow people to follow acquaintances, families and friends' lives, the number of people on social networks has grown exponentially since the turn of this century [1]. Facebook, Twitter, LinkedIn and MySpace are the most popular social networks with millions of members. These novel Internet applications have the additional advantage of extreme usability and accessibility.

This emerging form of the Internet and the WWW is known by the term "Web 2.0". The former structure (now known as "Web 1.0") was based primarily on passive access to content that someone else (usually a professional) created and published. The current trend facilitates the creation, assimilation and distribution of information and knowledge. There is a clear separation between highly popular Web 2.0 sites and the "old Web". Three kinds of shifts can be distinguished: technological (scripting and presentation technologies used to render the site and allow user interaction), structural (purpose and layout of the site), and sociological (notions of friends and groups) [2]. Web sites that have only some of the social Web 2.0 features, but not all, fall in an intermediate category: Web 1.5. At a technical level, Web 2.0 is based on small chunks of information, loosely interconnected through a range of standards and web services. Web 2.0 is blurring the boundaries, allowing consumers to be themselves the producers [3].

Web sites like Flickr and YouTube attract millions of users, who, even though they are not necessarily the content creators (of pictures and video, respectively), they can search, filter, evaluate, and comment on the available user-provided material, and assimilate it to their personal collections. Since the main content of Web 2.0 sites is multimedia content, we can detect a new approach in they way users manipulate multimedia data. Thus, the revolution of Web 2.0 also resulted in new ways of multimedia (and consequently music) production, management and distribution.

Apart from the software issues, the development of new hardware solutions plays a crucial role in the aforementioned multimedia manipulation of Web 2.0. Portable devices are the state-of-the-art media for producing, reproducing and delivering multimedia data over the web in an "anywhere anytime" manner. Average users own generic devices, such as mobile telephones, PDAs, portable computers and tablet PCs. These days, mostly entertainment devices (MP3 players, iPods, portable video game consoles etc.) deal with communicative and multimedia operations and have the same 
capabilities as personal computers (e.g. Internet connectivity, high quality graphics, etc.).

The case of the mobile phone is typical. Their evolution during the last few years was extreme and by now more and more mobile phones can capture and handle multimedia, connect to the Internet, and even locate their position through geographical positioning system [3].

Focusing explicitly on music, there is yet a number of solutions utilizing multimedia and Web 2.0 for the sale, playing and promotion of digital music files. Sheridan and Lonergan discuss some of the new technologies that are affecting how we listen to music [4]:

- Visual Radio.

- Music Players for Mobile Phones.

- Portable Game Consoles with Music Playing Capabilities.

- Agreements between Mobile Phone Companies and Music Companies.

- Media Centre Systems controlled from one Computer via PC.

Apart from general music software solutions, even operating systems give great emphasis in the multimedia web management in our days. Google Chrome OS is the new Google's operating system, which is mainly Internet-oriented.

The main fact behind the philosophy of this operating system is that there is a great amount of people that use their PC exclusively to connect to the Internet. Furthermore, Internet offers so many different options in our days (social networks, videos, e-mail, chat, music) that qualify our browser as one of the most important software parts in our PC. Google's general intent is to create an operating system as similar to a web browser (much more so Chrome). This led to the new operating system, which lacks of several functions of a traditional operating system that slowed down the actual online needs of a web user.

Users of Google Chrome OS are not supposed to store anything in their hard disks, since all the information will lie on the web and only web applications will be used. Google is based on the motto "everything in the web" and, therefore, also our music information will lie there. If a user wants to listen to a piece of music, he will have to browse the web, search for it and listen to the song directly from a web source, e.g. YouTube. The creation and uploading of a streaming playlist on a web server will also be a possible option to listen to our favorite music online.

What happens, however, in the case we have no access to the Internet? After all, the world is still not covered with a Wi-Fi blanket. For that reason, Google is focused on the creation of an offline application, possibly based on Google Gears.

Together with Google Chrome OS release, Google releases Google Music Beta, which is supposed to be the solution to music information management issues of Google Chrome OS. In particular, any user of Google Music Beta will be allowed to upload up to 20,000 songs on Google Music Beta's server from their PC (independently of their operating system). Then, they could connect to the Internet via a device (Chromebooks, Android for mobiles) and listen to their music online. At the same time, an offline mode of the application will be supported, in order for the user to play the last songs he listened to while he was online, or even choose which songs will be available for reproduction in Google Music Beta while not connected to the Internet. This approach (which is based on Cloud Computing) allows music data to be always online. The access to them will be achieved with a simple sync, without worrying about cables, file transfers and storage space on hard disks. Finally, the user will be able to upload any music data from any kind of source (different computers, i-tunes library etc.).

\section{Remodeling the Music Industry}

Music used to follow a specific procedure for its production until a few years ago. This procedure started from the idea's capture (by the composer) and, after several stages, ended to the reproduction of the final recording by a device. The procedure used to be the same without regard to the final recording medium (vinyl disks, tapes or even CDs). We will describe the changes, brought by MP3 and online radio, which took place in this procedure.

The music production process had several stages, which can be seen in Fig. 1. Considering a song as a product, its production process begins with the writing of music by the music composer and the writing of lyrics by the lyrist (these two roles may belong to the same person). Automatically, they own this composition's copyrights. Afterwards, the initial idea is processed by several artists: musicians, singers etc. The recording of the music piece takes place in a music studio, where sound engineers and computer programmers participate. After the recording, the production of copies (CDs, tapes etc.) follows. The product should be then packed in order to come out to market. Also several professionals worked in this stage: photographers, commercial artists and publishers. The final stage involves a promotion company that takes over the product's promotion in the market. The person in charge of the described whole process was a producer (usually representative of a record label). Although the recording usually took place in privately owned studios of the record label, the CDs production used to take place in third party facilities.

The advent of information technologies in music industry brought several changes to the production chain. A crucial point of the new confused situation 
in music production is the entrance of several stakeholders from the field of computer science, who had no association to the music industry before.

Online music distribution differs a lot from the traditional distribution of physical media, and saves a lot of money for the labels concerning the costs of manufacturing, packing, storing and delivering. Fig. 2 shows the new structure of digital music industry. Comparing to Fig. 1, there are obvious differences and additions from the traditional structure.
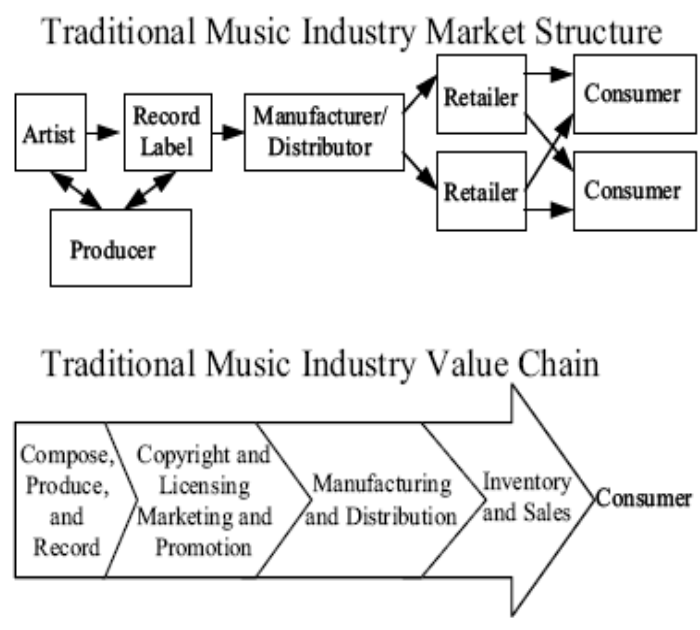

Figure 1. The traditional structure of music industry [5]

Digital Music Industry Market Structure

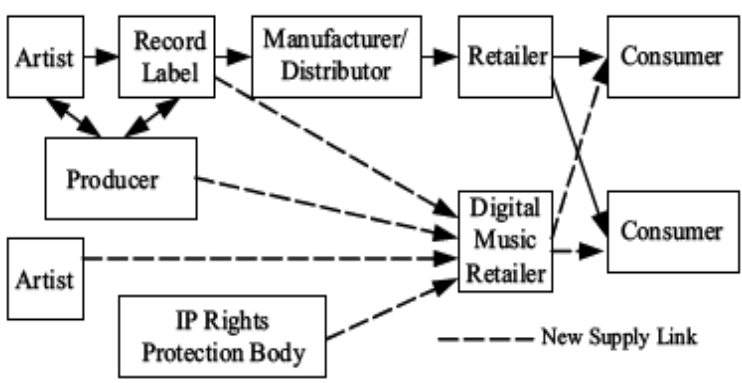

Figure 2. The structure of digital music industry [5]

The channel on top of Fig. 2 defines the traditional production chain. However, there are now two kinds of music consumers: those who buy the physical record products, and those who consume digital products (music files, streams etc.).The arrows with discontinuous lines define the new supply channels. Four out of those five arrows end in a new entity in the structure: digital music retailers (e-shops). In digital era, the traditional production process stops at recording, where the only engaged roles are: the producer, the artists and the record label (triangle on the upper left corner of Fig. 2). There is no need for hard copies and packages anymore. The digital form of music (bits) allows its cheap storing in a tiny disk. When the digital music file is ready, it is distributed to music websites and e- shops. Music labels and producers authorize such sites for the legal retail to consumers.

The third newly created channel has to do with the artists, who can now easily carry out the tasks of recording and production by themselves and peddle their songs directly to the Internet, as it is described in the next section.

\section{New Trends in Music Production}

The change in peoples' music preferences and the way music information is treated has resulted in a switch to new methods of music production. This transition can be demonstrated through the example of the revolutionary soundsystems, which appeared around 1950 in Jamaica. Soundsystems consisted of people (disc jockeys, mechanics and MC's) and machines that played and recorded music. Actually, they were music studios. However, apart from their music usefulness as studios, they were also used for live performances. Moreover, they had several other social and cultural effects, which are out of the scope of this paper. What is of interest here is the equipment of these soundsystems and the way an artist could plug his music through them.

In its simplest form, the mechanical parts of a soundsystem were: (at least two) turntables, a DJ mixer, headphones, microphones, public system / amplifier and a range of big sound boxes (especially for low frequencies), known as boxes and bass rings [6]. A disc collection was also necessary in order for this construction to be functional. The crew of a soundsystem consisted of the soundman (box man), the selector, the mixer and the disc jockey (DJ) [6]. Often, the soundsystems were housed in small vans, since the artists used to exploit their capabilities for their live performances. The description of soundsystems can clearly demonstrate the functionality of a simple music studio.

Regardless of the evolution in music production until the early millennium, the main features of recording music remained the same as in the case of soundsystems. Therefore, the procedure that an artist should follow to record his music ten years ago was as follows: the artist should work in a music studio, record his music, take the recorded material and give it to his music label (in the case he already had a contract) or send it to music labels as a promo. For a professional artist (i.e. for someone who has a contract with a label) the changes nowadays are not dramatic. The way of recording and producing music is more or less the same with the exception that there are yet lots of music software applications available.

The greatest changes have gone a long way towards the way an amateur musician or a simple PC user can now produce and promote their own music. It is a fact that, because of the evolution in computer music, each individual can now create their own music data and promote them at his pleasure. In the 
last decade, an exponential growth of music software has been observed. Moreover, this software is distributed freely via Internet (because of the increase in Internet piracy). Commercial software applications, such as Fruity Loops, Orion, Groovy, ReCycle, Jam Trax, Acid Music Studio etc. [7], are by now available to each user. Even a user without special knowledge on music production can use these applications without any cost and create a piece of music. As a result, more and more DJ's appear lately and there is an increase in the amount of electronic and instrumental music produced. Moreover, new amateur artists can promote their work by circumventing music labels. Social networking websites, forums and YouTube are their up-to-date promoting tools. The uploading of a music production on the afore-mentioned alternatives is an effective and costless way of promotion.

It should be also mentioned here that not only audio files are concerned in this process, but almost any information is related to the produced music. Even an amateur produced video-clip can be uploaded together with a music piece and be accessible by anybody. This is the result of the concurrent development of music software and hardware. For example, the new $i$-Phone offers the capability of high definition video recording. This means that a user will be able to direct, record and instantly upload a video clip in YouTube through a single mobile device! This goes round several steps of the traditional music production process. At the same time, this immediacy offers instant copyright protection to the artist. By uploading a music file or a music clip to the Internet, the literary property is automatically protected. Again, the inflexible structures in the field of copyright are avoided this way.

\section{New Trends in Music Distribution}

The key factor of digital music revolution was the discovery of $M P 3$ whose first public release date was in 1993. MPEG-1 Audio Layer 3, also known as MP3, is a patented digital audio encoding format using a form of lossy data compression. It is a common audio format for consumer audio storage, as well as a de facto standard of digital audio compression for the transfer and playback of music on digital audio players.

\subsection{Techniques for music files distribution}

The suitable format of MP3 files for music distribution over the Internet led to the creation of digital music libraries (DMLs). The Digital Music Libraries offer their users new ways of interaction with music repositories and music stores online. Some of the capabilities of Digital Music Libraries are: classification, filing and sharing of music, music information retrieval etc [8]. Next, we will present briefly the techniques that are used for the distribution of music files over the Internet.

4.1.1. File sharing. File sharing is defined as the technique of distributing or providing access to digitally stored data, such as applications, multimedia (music in our case), text files and e-books. It can be achieved via a wide gamut of transmission, storing and distribution models. Common file sharing methods are: manual sharing through removable media, centralized file servers in computer networks, web hyperlinks and distributed peer-to-peer networking.

4.1.2. Peer-to-peer sharing. Suitable software applications allow users to connect to a peer-to-peer network, where they can search for music files in other users' computers (peers) and download them directly. Although Napster has acted as a catalyst in music sharing over the web, it cannot be classified as a pure peer-to-peer network, since it was based on a centralized directory, which contained users' data [9].

4.1.3. File hosting services. File hosting services comprise a simple alternative to peer-to-peer services. They are usually combined with Internet tools, such as email, forums, blogs, or any other service that provides direct downloading via hyperlinks. File hosting pages typically offer files that can be downloaded to users' PCs.

\subsection{Music downloading options}

Next, we summarize the user options for downloading music files:

- File Server Pages, e.g. Rapidshare, Megaupload, Hotfile etc.

- Music-Specialized Server Pages, e.g. Albumsmart

- $\quad$ P2P Software, e.g. Kazaa, Shareaza, EMule, Limewire

- Bittorent Clients, e.g. U-Torrent

- Amazon

- i-Tunes

- Electronic Purchase of a Digital Record

\subsection{Models of digital music distribution}

In the digital era, the music industry is diversifying its business models and revenue streams. Many researchers have investigated the ways, which may transform the face of music industry and several new business models have been proposed. 
As far as the recording production procedure followed the classic way, there was only one business model: the traditional model. With the advent of the Internet and digital media, this model differentiated and, as a result, two new business models occurred: network models and hybrid models. An easy-to-use framework is presented in Figure 3 in order to classify the models into 4 categories [10]:

1. Traditional models (physical distribution / physical product)

2. Network models (online distribution / digital product)

3. Hybrid models (physical distribution / digital product OR online distribution / physical product)

4. Mobile distribution models

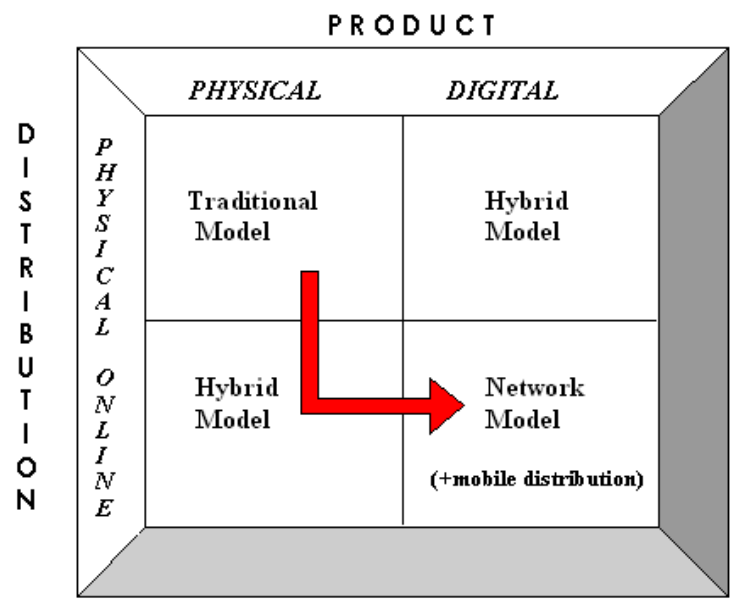

Figure 3. A framework for business models in the music industry. The arrow shows the transition from the traditional model to the Internet models thorough hybrid forms.

Almost all the newly appeared models are classified as Network models, especially the purely Internet models (prevention model, ad-supported model, subscription model, music locker, ala carte, etc.).

Regarding the ways of funding of the digital content distribution services, the digitized content can be distributed either by charging per "download" (pay per download), or for a fee per package (pay per bundle), or pay-per-use. The most prominent business models for music distribution in our days are: the 'a la carte' model, the subscription model and the ad-supported model. For example, the iTunes music store uses the "a la carte model" for charging the users per download. Rhapsody and (down recent times) Napster function through member subscriptions. On the other hand, Pandora, iMeem, MySpace and Last.fm offer the services wthout charging the users, as they are staked by advertisers (ad-supported model).
4.3.1. The a la carte model. The a-la-carte download model, pioneered by Apple iTunes, remains the largest revenue source in the online sector and has more than 100 million accounts across 23 countries. Recent innovations in the a-la-carte sector include the introduction of variable pricing, which has increased the conversion of track purchases to album sales, as well as the launch of the iTunes LP and the rollout of DRM-free downloads internationally.

According to IFPI, music companies have expanded their licensing of DRM-free a-la-carte services internationally. Fans can now transfer their purchased music files to different portable players when they buy from virtually any online service. Digital album sales grew faster than single track purchases in many markets. Variable pricing, by which catalogue music is discounted relative to new top charting tracks, helps increase the conversion of track purchases into album sales.

4.3.2. The subscription model. Music subscription is transforming the way people experience and pay for tracks and albums. It is also a fast-expanding business model. According to IFPI, the number of consumers subscribing to music services globally is estimated to have increased by nearly 65 per cent in 2011, reaching more than 13 million, compared to an estimated 8.2 million the previous year. This supplements the tens of millions of consumers who already use download services.

In 2011, subscription services made groundbreaking moves to achieve mass-market reach, most notably through their integration with Facebook, which has propelled music subscription into the environment of social networks. Under Spotify's partnership with Facebook, new sign-ups to Spotify come through Facebook and users then share their playlists with friends.

The changes, which advanced adoption of subscription services over the last few years, are [11]:

- The penetration of smartphones and connected devices mean a user is no longer tied to a desktop in order to consume subscription music

- Transition to cloud-based access, browser-based UIs and multi-device apps, make the experience portable

- Ability to use competing services like Rhapsody on dominant devices like an iPhone make those services more relevant

- Integration of social networking and services, such as the Facebook and Spotify tie-up, drives awareness and engagement 
- New and interesting services like Spotify, Rdio, Mog, Deezer, Galaxie and others

- Consumer adoption of video services like Netflix and Hulu are building a general acceptance of the subscription model

4.3.3. The ad-supported model. This model relies on the insertion of advertisements into copyrighted content. Users can listen to their favorite music, while (visual or auditory) ad spots are interpolated. This kind of advertisement may bring revenues for the payment of the stakeholders, as well as the copyright owners.

Recent studies show that ad-supported models provide an important channel of legitimacy for many downloaders, are already helping to stave off filesharing, and have the potential to do so even more in the future.

\subsection{The advantages of digital music}

There are several reasons why people embraced digital music format. The user is able to download any songs anytime, without visiting a traditional music store. Any music piece can be downloaded in a few seconds thanks to the increase of network connection speeds. Another reason is the dramatic growth of Internet piracy. Songs are freely distributed over the Internet (in some cases even before their official market release).Thus, the users do not need to pay a price to buy a CD. Instead, they can simply click and download their favorite songs, without thinking about label contracts and copyright issues. This issue has resulted in a controversial ethical and legal battlefield, which is described in section 7. A last advantage of this shift towards digital music is the ease of music storing and transferring. CDs and vinyl are concrete. Contrarily, downloaded music is simply bytes in our hard disk. Therefore, instead of filling our shelves with music media, we fill our hard disks with bytes of music. This serves for two reasons: it saves space and makes distribution easier.

\subsection{The evolution of networking and how it affected digital music distribution}

New evolving communication networks offer better ways of socializing and data exchanging. These networks have even managed to threaten the structure of music industry as it has already been presented in section II. Taking into account Metcalfe's law ("a network is as powerful as the number of the users") and Reed's law ("a network is as powerful as the number of users x users") [12], we can conclude that the Internet forms a powerful entity.
The ways of music distribution have been altered in our days. In the past, a very large amount of legal and pirate music files had already flooded the Web. The revolutionary Napster software had caused several reactions. Since then, big changes have contributed to digital music distribution over the Internet.

First of all, we should stress the importance of Internet transmutation. Web 1.5 is being gradually replaced by Web 2.0 since the beginning of the millennium, which absolutely affects the distribution of music data.

Network speed has increased. The available speed and bandwidth in 2000 seems negligible compared to recent standards. The dominant Internet line in Greece was ISDN (maximum $128 \mathrm{kbps}$ ) ten years ago. Now, most of citizens own their personal DSL line, which offers up to $24 \mathrm{Mbps}$ (192 times faster).

Considering the slow network speed of the last decade, it becomes clear that downloading music would be a serious decision these days. This decision would probably constrain all the bandwidth, resulting in the inaccessibility of the rest of the web. On the other hand, if the user had set a maximum bandwidth limit for music downloading (so as to browse the Internet at the same time), he might wait even for days in order for his download to be completed. Today's offered bandwidth allows downloading music as a hobby. Internet users have reported that they may download full music albums (without ever listening to them!) either because their lines are idle at a time, or because they need just one song and consider downloading the full album as a good idea. Let's not forget that users can now download in a day the amount of songs that they could download in a week some years ago. We can conclude that music downloaders have become greedy since they are more interested in the music information volume rather than the information itself.

Moreover, we should not relate the Internet only to personal computers as we did a decade ago. Nowadays, the connection to the World Wide Web and network services can be established via lots of other devices (mobile phones, i-pods etc.). Therefore, music distribution does not only relate the Internet to personal computers, but also to portable devices, and portable devices to personal computers. These new relations have set innovative standards to music distribution and have given cloud computing a boost.

Another fact of the Internet's evolution has to do with the growth of music information. Possibly, a music file would not exist in the web a decade ago. Yet, almost anything can be found either on pay sites or on pirate sites. This is the result of a modern Internet user's attitude. Users have the tendency to upload too much information about themselves and their own preferences on the Internet. This fact results in exponential growth of music distribution in 
novel ways. Song posts on Facebook, embedded media players in blogs, comments and video responses in YouTube are some of them.

Let's take into account some actual numbers. Facebook numbers more than 500 million members and about 50 percent of them are active daily. Each of them has an average of 130 contacts (friends). The average amount of total posts is almost 30 billion posts per month. Some million posts out of these 30 billion concern music posts. This social way of music distribution is much more different than the direct way of MP3 files downloading. These posts do not provide links to music files. Instead, they link to multimedia streaming sites (the overwhelming majority links to YouTube). These posts create and make up music preferences. Therefore, their contribution to digital music distribution could be qualified as indirect. This trend has its roots to social networking web pages that have pushed users towards this direction.

Together with the increase of music volume, another phenomenon that has increased dramatically over the last decade is piracy. A serious matter that should be examined is the non-conscious piracy. Most users distribute music in some degree over the Internet. If music files are concerned, then there is a great possibility for the transfer to be illegal. However, the paradox in this action is that the user is not aware of that!

Apart from the increase in distributed music data, there is also an increase in the amount of web sites that manage and distribute them. A few years ago, only Napster and some P2P software (with limited potential and audience) existed. Now there are more choices for the user that result in faster and easier ways of data sharing.

\section{New Trends in Music Management}

The issues involved in music information retrieval a decade ago were mainly: the possible absence of the information from the web, the network speed and the sources related to the desired information. This is not the case anymore. In our days, the most significant factor in music retrieval is the way that the user looks for specific information in the web. In order to comprehend the meaning of this statement we should investigate the changes in music management during the last years.

Web 2.0. describes websites of the second generation. These sites, which appeared for the first time 5 years ago, front for the emerging turn in the way the Internet brings producers and consumers in touch. Although it could be characterized as a technological revolution, this new trend applies mostly to the creation of relations between information producers and consumers via the Internet [13].
The outcome of this evolution is several sites that are fed with content and data by their administrators, but are also enriched and updated by the users, e.g. YouTube. The content of such a site does not come from any organization or manufacturer. Users add content for community's sake. Thus, the user himself becomes the information distributor. The form of digital communities allows the users to interact with each other by offering communication options. For instance, YouTube allows the posting of comments regarding each video in case the uploader of the video allows it. Moreover, each user owns his personal channel in the site. We are then to conclude that the self-managed websites of the last decade, which were fed with content by their manufacturers and administrators, are replaced by websites that function and are fed with content by the collective effort of online communities.

Music information management has reached a new level lately. The user is not exclusively based on media sites in order to acquire music files and information. The plain articles and the inflexible structures have been replaced by the newly offered interactive options [14]. Users can now easily read comments and reviews by other users, post their own comments, download or just listen to a music piece. All these capabilities make the user part of a continuously evolving community.

How does the current user manage the huge volume of music information? The answer is quite simple: with additional information or metadata. Metadata are data that define other data and are structured through a tagging system. We will next explain how one of the main and most popular tagging systems for MP3 files work in order to better comprehend its role. ID3 tag is a piece of information that is put in front of a music file. Its size may reach $256 \mathrm{MB}$ and it consists of several fields, whose size is at most $16 \mathrm{MB}$. These fields form a space, where the metadata are stored. The tags contain several data regarding a music piece: the name of the artist, the track number, even the lyrics of the song! They may contain images, other files or even information about the way of music reproduction, e.g. equalization and balance settings. The first ID3 version was created by Erick Kemp and provided a fixed tag size of 128 bytes. The tag of the first version lies on the end of a music file, which made the system unsuitable for streaming applications. Considering the great difference in tags' size (128 bytes in 1996 - 256 MB today), we can realize the absolute necessity for metadata. This is reflected in the way of nowadays' music management, comparing to the needs of 1996.

When tags are added in an object, this can be linked to other objects (that bear the same tags) in social networking sites via search engines and hyperlinks. This way, playlists with online content 
can be created. The result is defined as tag cloud [13].

Object tagging has led to even more changes. At the moment, the results of a music information search query (e.g. via Chrome) in the Web can be millions. The user does not confine his search to specific centralized music sites, but has a lot of options for both music information and music downloading. The use of metadata may bring to light too much related information regarding the desired music piece, the artist, his past and future live performances, his biography etc. At the same time, there are many (legal and illegal) options to download a song. Finally, special utilities have been developed in order to facilitate these options, e.g. web pages translation by Chrome browser.

The aforementioned provided options led to some fundamental changes in the way the user manages music files and music information. In particular, if somebody wanted to listen to a song a decade ago, he should either download it to his disk or listen to a web stream. Nowadays, the user may simply navigate in YouTube and listen to the songs he wants.

Why would someone download music files to his disk, when he is able to simply listen to them from the Internet anytime he wants? It can be concluded that the need for music downloading is gradually being replaced by online music options. Cloud computing advances by leaps and bounds, while the philosophy of the new Google operational system shows that the science of networking rips along this direction.

Considering the large volume of music files and metadata that exist today, nobody can be $100 \%$ sure for what exactly has been downloaded to his hard disk. One plus one is not necessarily equal to two in the field of music information anymore. One plus one may also be equal to one. This will be next explained via an example. Imagine that a single user has $40 \mathrm{~GB}$ of music files stored in the disk of his personal computer. $40 \mathrm{~GB}$ of music files almost correspond to $11,000-12,000$ different songs. Considering that this user is provided by an extra 20 GB of music (which means about 5,000-6,000 different songs), is it safe to conclude that the user would finally own 17,000 songs in his disk? This is, of course, true in the case of counting the music files. However, this is not true in most of the cases considering the amount of music information. These song collections may overlap, which means that files with the same music content, but different names or metadata, may exist. For example, the user may own

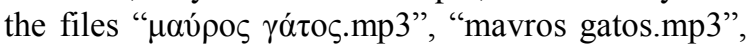
"mabros gatos.mp3" and "track17.mp3", which all contain the same music content but take up different space in his hard disk and are recognized as four different songs for the computer.
From this short example it should be clear that one plus one equals to one since the same music information is offered with different naming. There are not yet classification methods for this problem, except for the manual seek and destroy, which is a hard and time-consuming user process, almost impossible to be applied in very large volumes of music files. To conclude, if we draw a parallel between the World Wide Web and a user's personal computer, we can realize that the same data exist multiple times, resulting in user's preference to online music information rather than the traditional music file downloading that prevailed during the last years.

\section{Music and Cloud Computing}

Cloud computing refers to the use of computing power, which is spatially located in a "cloud" of remote networks. Cloud computing means large data centers, which offer economies of scale, cheaper computing power and most importantly, flexibility to pay for only what you use.

As far as cloud computing for digital music is concerned, there is no need to store music files on hard disks and flash disks. Music files are stored in a "cloud" of servers distributed around the world, while the network devices gain access to music collections wirelessly from remote servers. With cloud computing, digital stores such as iTunes, can offer unlimited access to millions of songs with a monthly subscription.

Cloud computing offers a range of advantages:

- Optimal use of resources. Cloud computing reduces costs and maximizes usability since resources are only available when required.

- Flexibility. There is no risk for information loss since all systems and software applications remain constantly available.

- Access from everywhere. Cloud computing enables access to applications and data from anywhere in the world, safely encrypted through internet.

- Cooperation. Having the applications and data accessible from the cloud, collaboration between people becomes easier since users can work simultaneously on the same project.

- Disaster recovery. Disaster recovery procedures can be automated via cloud computing by using backup and maintaining servers, especially designed to act as images of the main servers.

Among the great companies, which work on cloud computing software for digital music distribution 
over the Internet are: Google, Amazon, Apple, Microsoft, Saleforce.com, Dropbox, SugarSync and Box.net.

\section{Online Piracy and the Legal Battlefield}

The revolution of digital music also resulted in incontrollable illegal distribution of the vast amount of digital music in the Internet. While most parties involved agree that violation of music copyright laws and music royalty payments devastates the music industry, they have not concluded to specific, justifiable and proportional measures that punish the ones that deliberately share copyrighted music [15].

In the USA two laws have been proposed in 2011: the Stop Online Piracy Act (SOPA) and the PROTECT IP Act (PIPA). These acts have provoked considerable reaction this year. Protests were based on concerns that the bills, intended to provide more robust responses to copyright infringement (in simple words 'piracy') arising outside the United States, contained measures that could cause great harm to online freedom of speech, websites, and internet communities. Protesters also argued that there were insufficient safeguards in place to protect sites based upon user-generated content.

Among the protesters were significant personalities, like the Inventor of WWW Sir Tim Berners-Lee as well as the European Commission and many others. The former stated that such measures were harming the "openness of the Internet" instead of charging the ones really guilty. After that, the future of SOPA and PIPA is rather volatile.

Alternatively, to alter the vague state reported for law enforcement, ACTA was proposed. ACTA stands for Anti-Counterfeiting Trade Agreement and is a multinational treaty aiming to establish international standards for intellectual property rights enforcement [8]. ACTA aims to become the higheststandard plurilateral agreement ever achieved, coping with the enforcement of intellectual property rights. However, this legal action has not produced yet concrete and specific legal texts; it is focusing rather on the establishment of an international legal framework that copes with counterfeit goods, generic medicines and copyright infringement on the Internet. It could create a new governing body outside existing forums, such as the World Trade Organization, the World Intellectual Property Organization, or the United Nations.

ACTA was not coping only with and copyright infringement on the Internet; it targeted also counterfeit goods and generic medicines. When it comes to the Internet, it seems that the ACTA forced more or less signatory countries to adopt a "graduated response" to the file sharing users downloading copyrighted music files or films. So the signatories should provoke more or less criminal sanctions for inciting, aiding and abetting infringements, provided that a willful trademark counterfeiting and copyright or related rights piracy is detected on a commercial scale.

In more simple words, the treaty more or less bypassed the sovereign laws of participating nations, and forced ISP's around the globe to act as Internet police. Although there is a hilarious tone correlating this notion with histories from the 1980's when Hollywood lobbies reacting hysterically in the fear of the emerging video recorders tried to outlaw the distribution of such devices, the story with ACTA is quite different: Within copyright law there is direct infringement (involving the person who committed the infringement) and indirect or secondary infringement (concerning the ones that facilitate others in committing the infringement). In general, the Internet community and especially law makers should be wary of secondary liability issues, because they can create chilling effects for new innovations.

However, in the paradigm of music distribution, it is obvious that there is a synergy of a search engine along with a torrent or magnet link repository in order to commute music parcels. In a crafty manner, we have seen intermediaries disguising themselves to moderators for the music trafficking, while the real exchange is allegedly a peer to peer transaction. Consequently, the treaty considers transactions that would normally be considered non-commercial file sharing (which is potentially against the law, but in most cases it is no big deal), and transforms it into commercial scale criminal infringement. Similarly, it broadens the definitions about inducement and/or secondary liability to make what had been a civil (between two private parties) issue a criminal aiding and abetting. A criminal charge of aiding and abetting or accessory can usually be brought against anyone who helps in the commission of a crime; in this sense a torrent search engine that would enable its users to locate unlawful files could be directly targeted.

In this point many recall that this attitude reflects the model of some counties for a censored Internet; and indeed a surveillance system has been deployed. Critics of the treaty fear that by ACTA this model could be legally exported.

And things could be worse. There are parts of ACTA that effectively seek to upgrade what would normally be a civil infringement, i.e. a liability dealt between two private parties, to a criminal offence. A criminal offence is a much more serious matter compared to a civil infringement. It depends on a range of factors that epitomize the magnitude of the illegal activity. These are: the type of activity, including whether payment is received, the provoked damage to the music industry taking into account the multiplier effect, forgery, imposture and other frauds, etc. Criminal offences provoke the police to enforce 
the law exerting their investigative powers and are punishable by several years of imprisonment.

In a few words ACTA could reshape Internet surfing from fun to a nightmare. Moreover, it brings to surface a broader scope that has the mentality of devising new tools targeting "Internet distribution and information technology".

Fortunately, forecasts were confirmed the treaty was voted down by the European Parliament in July 2012, precluding that way any possibility for the European Union to ratify this controversial international treaty, which could threaten civil liberties, human rights and privacy of Internet users.

\section{Conclusions}

Internet has penetrated into our everyday life in every possible way. As a result, not only the volume of users has increased, but also their familiarity with the World Wide Web. As far as music is concerned, more users means larger potential volume of music information distributed, while more familiarized users means greater convenience and more distribution channels. At the same time, the contemporary Internet structure, combined with the revolution of social networks, led to the exhibition of many new artists. New music groups and independent artists do not target on the music labels for their promotion. In contrast, they use social networks and YouTube for their exposure. Music is everywhere in the web and can be found and consumed through numerous software and hardware (even portable) solutions. In addition, music is free for those who are not interested or informed about copyright issues and agreements.

\section{References}

[1] B. Huberman, D. Romero, and F.Wu, "Social Networks that Matter: Twitter under the Microscope', in First Monday, Vol. 14, No.1-5, 2009.

[2] G. Cormode and B. Krishnamurthy, "Key Differences between Web 1.0 and Web 2.0.", in First Monday, Vol. 13, No. 6, 2008.

[3] P. Siozos and G. Palaigeorgiou, Educational Technologies and the Emergence of E-learning 2.0, in Elearning Methodologies and Computer Applications in Archaeology, Published by Information Science Reference, ISBN:978-1-59904-759-1, May, 2008, pp.1-17.

[4] H. Sheridan and M. Lonergan, A Web 2.0 and Multimedia Solution for Digital Music, in Proceedings of the 7th Information Technology and Telecommunications Conference ITandT 2007, October 25-26, Dublin, Ireland, pp.98-105.

[5] J. Bockstedt, R. Kauffman and F. Riggins, The Move to Artist-Led Online Music Distribution: Explaining Structural Changes in the Digital Music Market, in
Proceedings of the 38th Hawaii International Conference on System Sciences HICSS'05, Vol. 7, 2005, pp. 180a.

[6] J. Constantinides, The Sound System: Contributions to Jamaican Music and the Montreal Dancehall Scene, (M.A.) Faculty of Music, Department of Ethnomusicology, Universite de Montreal, 2002.

[7] J. Heyworth, Jumping through 'Loops': a Reflective Study on preparing Generalist Pre-Service Teachers to teach Music, Issues in Educational Resarch,Vol.21, No.1, 2011, pp. 42-64.

[8] D. Margounakis and D. Politis, Implementation and Interaction Issues in Digital Music Libraries, WSEAS Transactions on Systems, Vol. 9, No. 2, 2010, pp. 146-155.

[9] R. Burnett, Music and the Internet, in The Handbook of Internet Studies, published by Willey Blackwell, ISBN: 978-1-4051-8588-2, April, 2011, pp. 440-451.

[10] D. Margounakis, D. Politis and C. Boutsouki, Providing Free Music over the Internet - Making Profits out of an Ad-Based Business Model, in Proceedings of the 2nd International Conference on Web Information Systems and Technologies: Society, e-Business and e-Government / e-Learning (WEBIST 2006), Setubal, Portugal, 2006, pp. 93-99.

[11] K. Drost, "Can Subscription offer Salvation for the Music Industry?", in Digital Pennies: Digital Media Strategy, Innovation and Market Trends, January 24, 2012.

[12] J. Hendler and J. Golbeck, Metcalfe's Law, Web 2.0, and the Semantic Web, Web Semantics: Science, Services and Agents on the World Wide Web, Vol. 6, No. 1, 2008, pp. 14-20.

[13] J. Knowles, A Survey of Web 2.0. Music Trends and Some Implications for Tertiary Music Communities, Proceedings National Council of Tertiary Music Schools Conference 2007, Music in Australian Tertiary Institutions: Issues for the 21st Century, June 29 - July 1, Queensland Conservatorium Griffith, University, Brisbane, Australia.

[14] T. Patokos, A New Era for the Music Industry: How new Technologies and the Internet Affect the way Music is Valued and have an Impact on Output Quality, Panoeconomicus, Vol.55, No.2, 2008, pp. 233-24.

[15] D. Politis, Music Libraries: The Legitimate and Ethical Battlefield of Music Distribution. Recent Researches in Communications and Computers, 2012, pp. 237-242. 